Supporting Information

\title{
Terpene Based Sustainable Elastomer for Low Rolling Resistance and Improved Wet-grip Application: Synthesis, Characterization and Properties of Poly(styrene-co- myrcene)
}

\author{
Preetom Sarkar and Anil K. Bhowmick* \\ Rubber Technology Centre, Indian Institute of Technology Kharagpur \\ Kharagpur - 721302, West Bengal, India \\ *Corresponding author: Email: anilbhowmick@gmail.com (AKB) \\ Tel.: +91 (3222) 283180; Fax: +91 (3222) 220312
}

Total number of pages: 19 (S1 - S19)

Total number of figures: 17 (Figure S1 - Figure S17)

Total number of tables: 5 (Table S1 - Table S5) 


\section{CONTENTS}

Figure S1. The ground state optimized structures of styrene and $\beta$-myrcene.......................S3

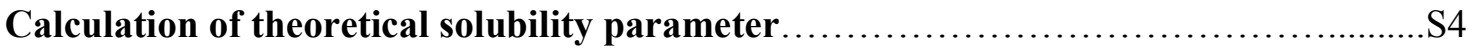

Table S1. Group Contributions for Theoretical Solubility Parameter ......................S4

Figure S2. FTIR spectra of Poly(ST-co-MY) copolymers with varying ST content.............S5

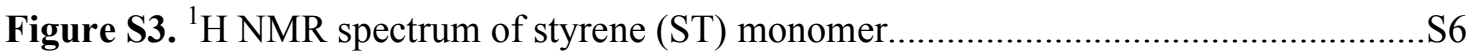

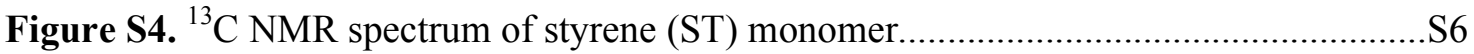

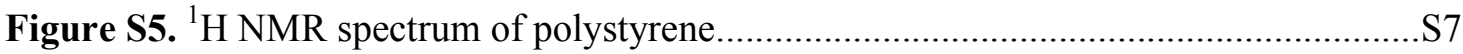

Table S2. Composition and microstructures of various copolymers as analyzed by ${ }^{1} \mathrm{H}$ NMR

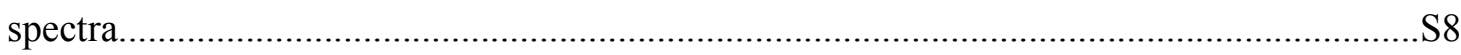

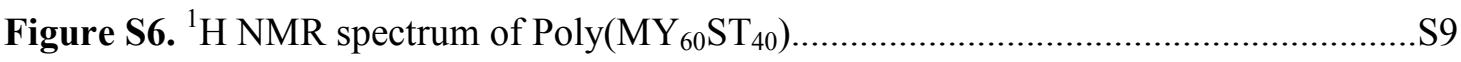

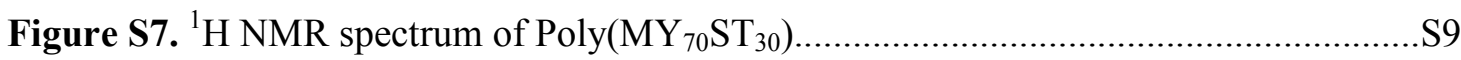

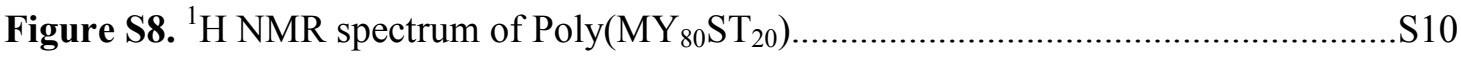

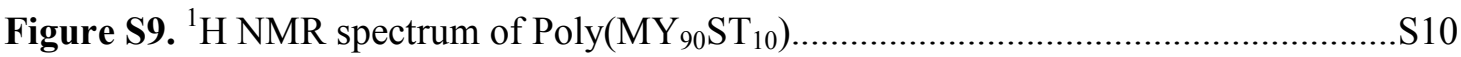

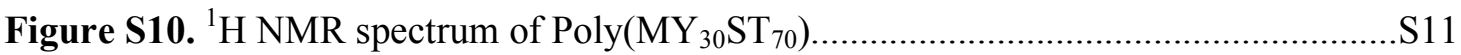

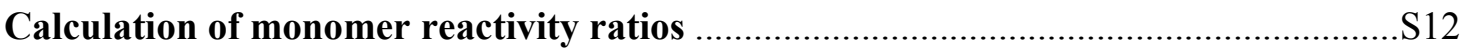

Table S3. Parameters for Calculation of Reactivity Ratio of MY and ST ...............S13

Figure S11. Plot of ST mole fractions in feed and copolymer.........................................S13

Figure S12. X-ray diffractograms of various synthesized polymers................................S14

Table S4. Glass Transition Temperature of Various Polymers..........................................S14

Figure S13. DSC traces of various homo and co-polymers.............................................. 15

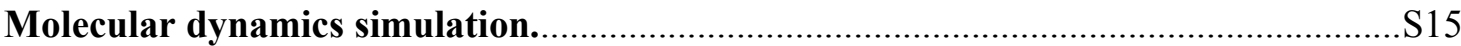

Table S5. Characteristic Degradation Temperatures and Percent Residue at $750{ }^{\circ} \mathrm{C}$.........S16

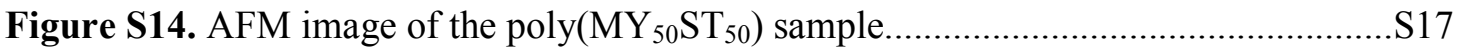

Figure S15. Room temperature plot of (a) storage modulus as a function of percent strain and (b) complex viscosity versus angular frequency for various copolymers.

Figure S16. Plot of complex viscosity versus angular frequency for Poly $\left(\mathrm{MY}_{0} \mathrm{ST}_{100}\right)$

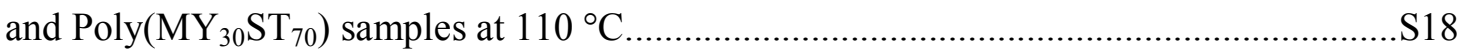

Figure S17. Variation of $\mathrm{G}_{\max }^{\prime}$ and temperature at $\operatorname{Tan} \delta_{\max }$ with styrene content...............S18

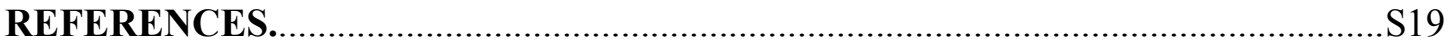




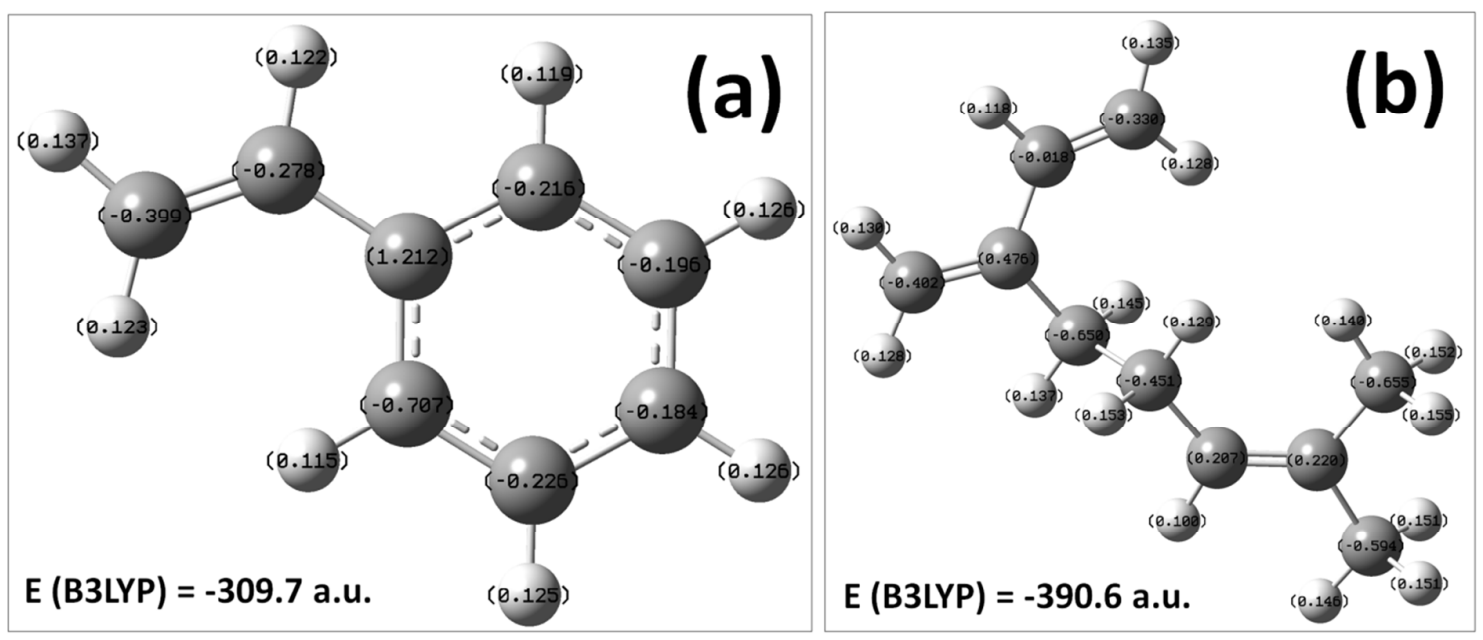

Figure S1. The ground state optimized structures of (a) styrene and (b) $\beta$-myrcene in B3LYP/6-311G (d, p) basis set. carbon: grey colour, hydrogen: white colour. The values indicate the Mulliken charges of the respective atoms. E(B3LYP) stands for Exchange correlation energy, Becke, three-parameter, Lee-Yang-Parr exchange-correlation function. 


\section{Calculation of theoretical solubility parameter.}

The theoretical solubility parameter was calculated by the method of Hoftyzer and van Krevelen. According to the group contribution principle, the solubility parameter components may be predicted using the following set of equations:

$$
\delta_{d}=\frac{\sum F_{d i}}{\mathrm{~V}} ; \delta_{p}=\frac{\sqrt{\sum F_{p i}^{2}}}{\mathrm{~V}} \text { and } \delta_{h}=\sqrt{\frac{\sum E_{h i}}{\mathrm{~V}}}
$$

Thus, the corresponding equation for determination of solubility parameter $(\delta)$ can be written:

$$
\delta^{2}=\delta_{d}^{2}+\delta_{p}^{2}+\delta_{h}^{2}
$$

where, $\delta_{d}, \delta_{p}$, and $\delta_{h}$ are the contributions of dispersion forces, polar forces and hydrogen bonding respectively. $F_{d i}$ and $F_{p i}$ are the molar attraction constants for dispersion and polar forces. $E_{h i}$ is the cohesive energy for hydrogen bonding and $\mathrm{V}$ is molar volume of the structural unit of the polymer. Table S1 enlists values of these parameters for various structural units.

Table S1. Group Contributions for Theoretical Solubility Parameter (Reference 42)

\begin{tabular}{ccccc}
\hline $\begin{array}{c}\text { structural } \\
\text { units }\end{array}$ & $\begin{array}{c}F_{d i} \\
\left(\mathrm{MJ} / \mathrm{m}^{3}\right)^{1 / 2} \cdot \mathrm{mol}^{-1}\end{array}$ & $\begin{array}{c}F_{p i} \\
\left(\mathrm{MJ} / \mathrm{m}^{3}\right)^{1 / 2} \cdot \mathrm{mol}^{-1}\end{array}$ & $\begin{array}{c}E_{h i} \\
\mathrm{~J} \cdot \mathrm{mol}^{-1}\end{array}$ & $\begin{array}{c}\mathrm{V} \\
\mathrm{cm}^{3} \cdot \mathrm{mol}^{-1}\end{array}$ \\
\hline$-\mathrm{CH}_{3}$ & 420 & 0 & 0 & 33.5 \\
$-\mathrm{CH}_{2}-$ & 270 & 0 & 0 & 16.1 \\
$=\mathrm{CH}-$ & 200 & 0 & 0 & 13.5 \\
$>\mathrm{CH}-$ & 80 & 0 & 0 & -1.0 \\
$=\mathrm{CH} 2$ & 400 & 0 & 0 & 28.5 \\
$=\mathrm{C}<$ & 70 & 0 & 0 & -5.5 \\
$>\mathrm{C}<$ & -70 & 0 & 0 & -19.2 \\
$-\mathrm{COO}-$ & 390 & 490 & 7000 & 18.0 \\
Phenyl & 1430 & 110 & 0 & 71.4 \\
\hline
\end{tabular}




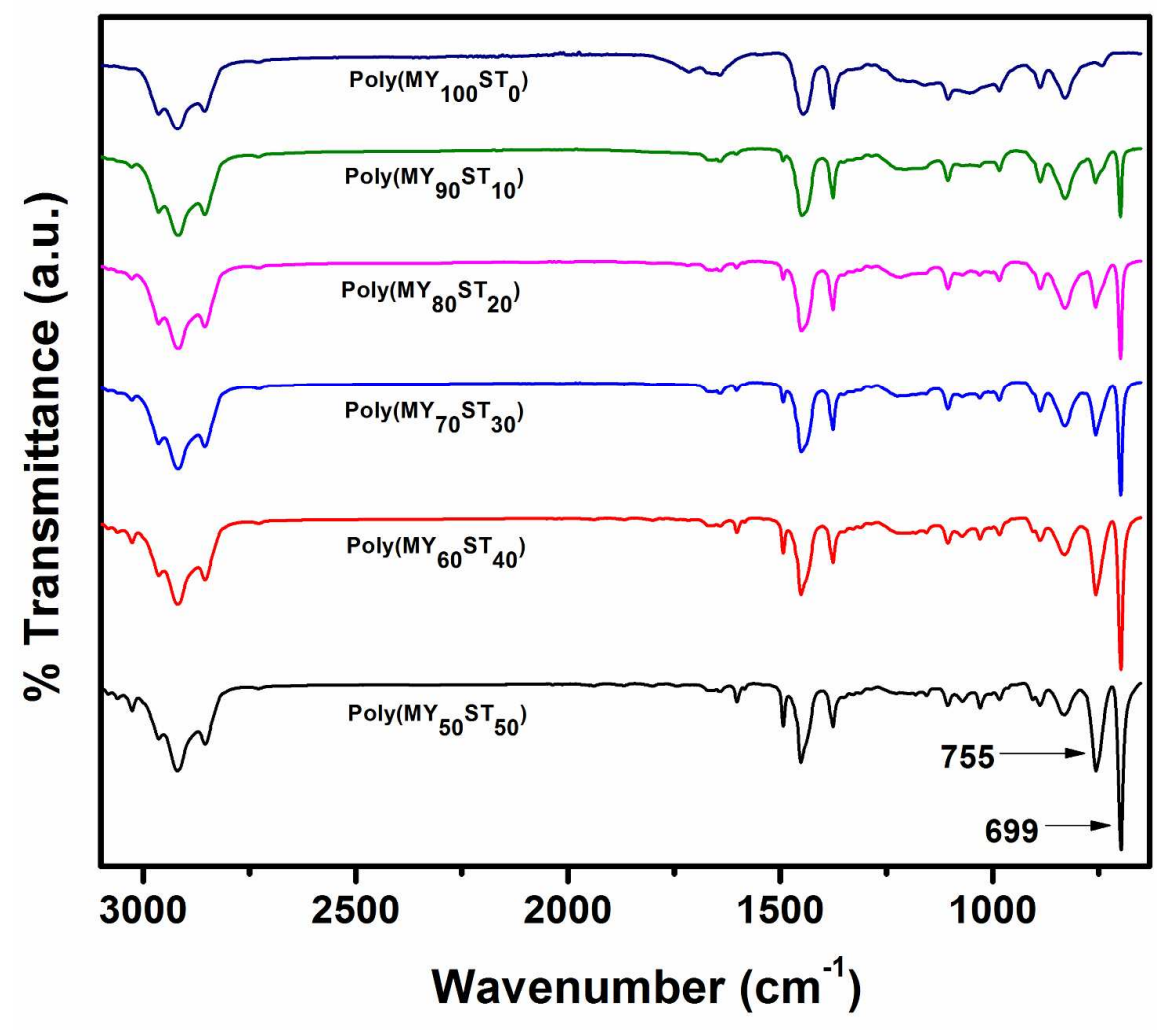

Figure S2. FTIR spectra of Poly(ST-co-MY) copolymers with varying ST content. 


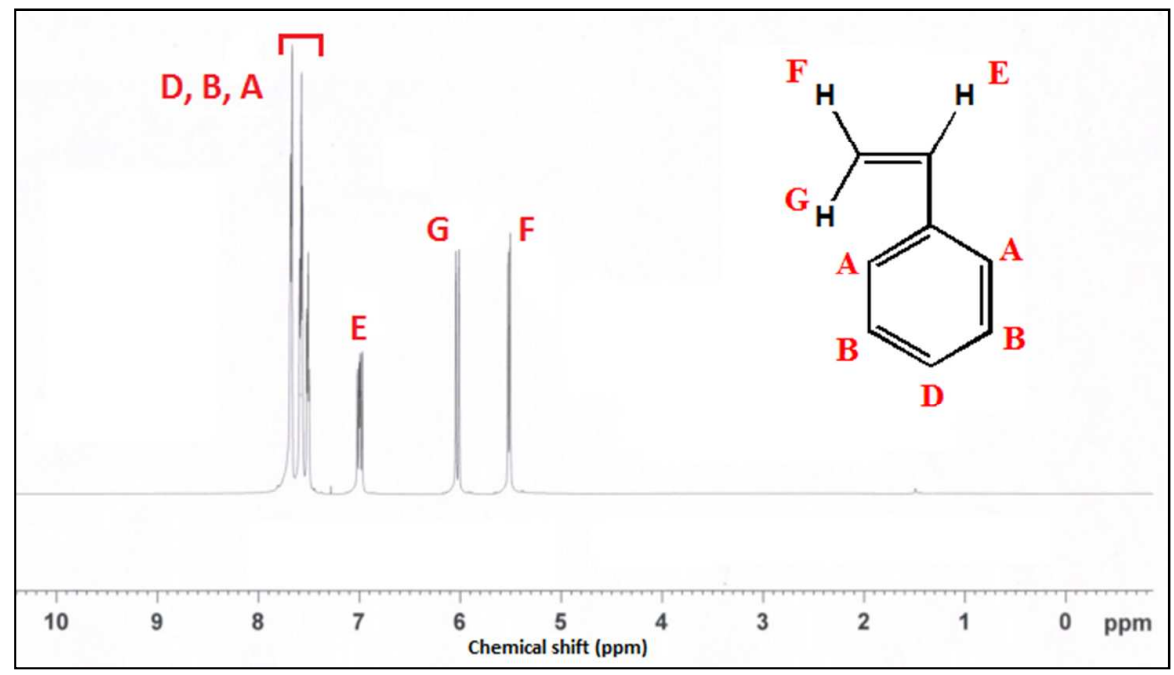

Figure S3. ${ }^{1}$ H NMR spectrum of styrene (ST) monomer.

Styrene (ST): ${ }^{1} \mathbf{H}$ NMR (CDCl 3 , 400 MHz): $\delta$ - 7.68 (1H, D), 7.58 (2H, B), 7.49 (2H, A), $7.00(1 \mathrm{H}, \mathrm{E}), 6.04(1 \mathrm{H}, \mathrm{G}), 5.52(1 \mathrm{H}, \mathrm{F})$.

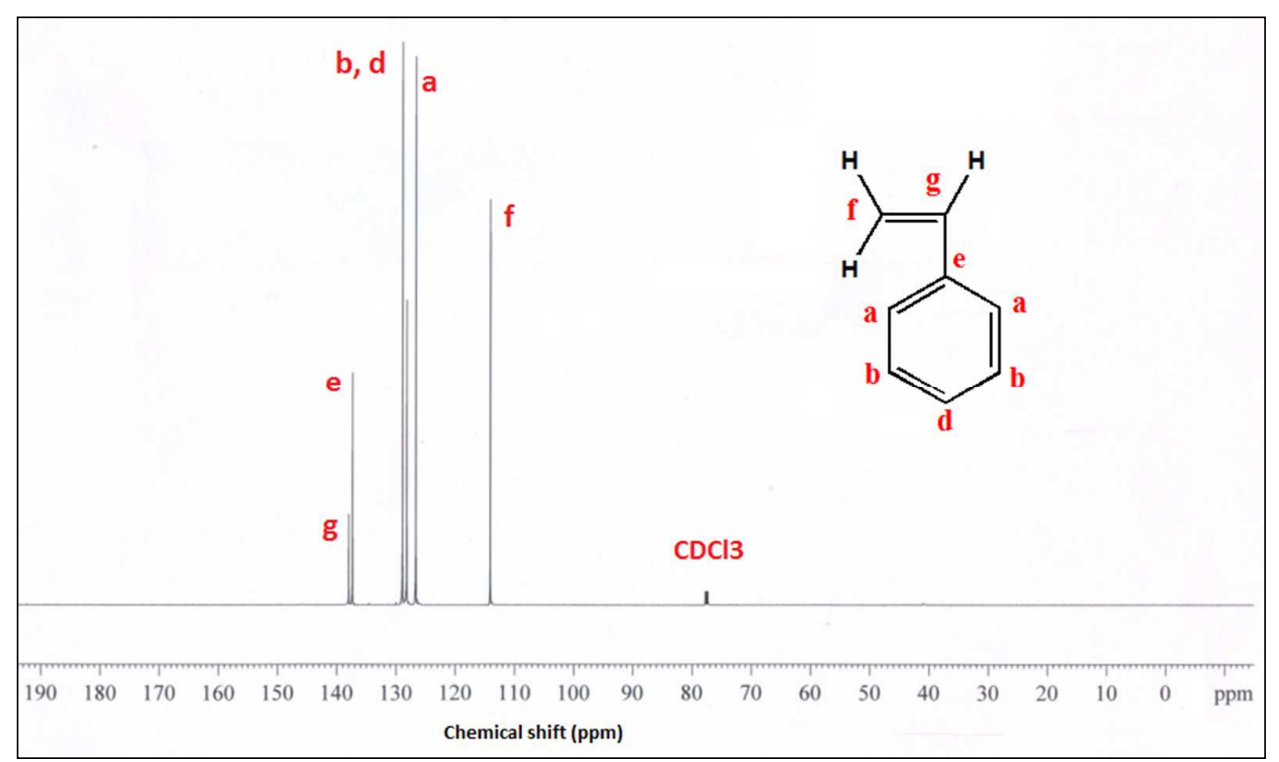

Figure S4. ${ }^{13} \mathrm{C}$ NMR spectrum of styrene (ST) monomer.

Styrene (ST): ${ }^{13} \mathbf{C}$ NMR (CDCl 3 , 400 MHz): $\delta$ - 138.0 (g-C), 137.3 (e-C), 129.0 (b-C), 128.1 (d-C), 126.6 (a-C), 114.0 (f-C). 


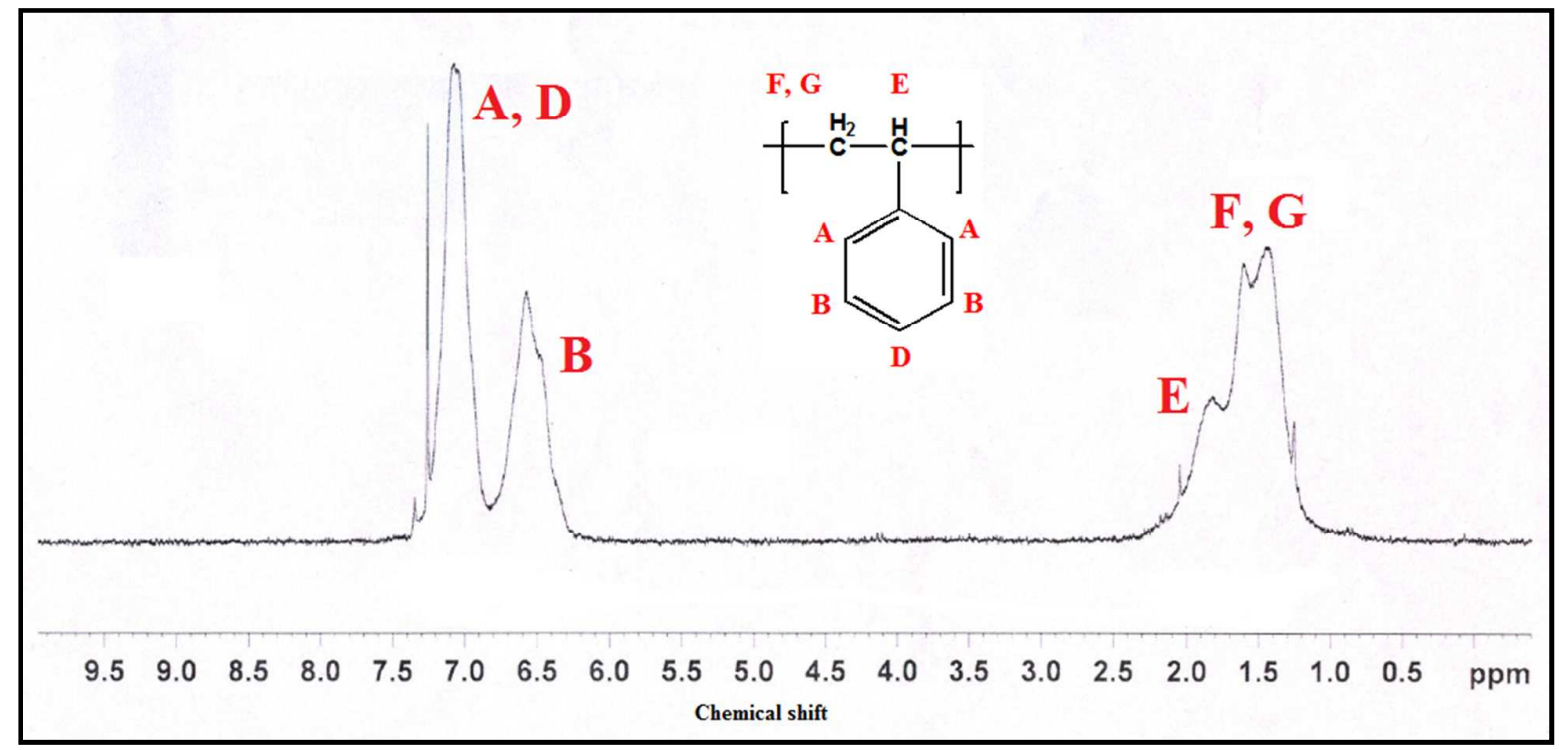

Figure S5. ${ }^{1}$ H NMR spectrum of polystyrene.

Polytyrene [Poly(MYOST100)]: ${ }^{1} \mathbf{H}$ NMR (CDCl 3 , 400 MHz): $\delta-7.26-7.08$ (3H, A and D), $6.58(2 \mathrm{H}, \mathrm{B}), 1.82(1 \mathrm{H}, \mathrm{E}), 1.61-1.43(2 \mathrm{H}, \mathrm{F}$ and $\mathrm{G})$. 
Table S2. Composition and microstructures of various copolymers as analyzed by ${ }^{1} \mathbf{H}$ NMR spectra.

\begin{tabular}{|c|c|c|c|c|c|}
\hline \multirow[b]{2}{*}{ copolymer } & \multicolumn{2}{|c|}{ composition } & \multicolumn{3}{|c|}{ copolymer microstructure (in \%) } \\
\hline & $\begin{array}{c}\text { theoretical } \\
\text { feed charged } \\
\text { MY/ST }\end{array}$ & $\begin{array}{c}\text { copolymer } \\
\text { MY/ST } \\
\text { from } \\
\text { NMR }\end{array}$ & $\begin{array}{l}- \text { cis and - } \\
\text { trans } 1,4\end{array}$ & 1,2 vinyl & $\begin{array}{c}\text { 3,4 addition } \\
\text { unit }\end{array}$ \\
\hline Poly $\left(\mathrm{MY}_{100} \mathrm{ST}_{0}\right)$ & $100 / 0$ & $100 / 0$ & 47 & 29 & 24 \\
\hline Poly $\left(\mathrm{MY}_{90} \mathrm{ST}_{10}\right)$ & $90 / 10$ & $91 / 9$ & 45 & 28 & 27 \\
\hline Poly $\left(\mathrm{MY}_{80} \mathrm{ST}_{20}\right)$ & $80 / 20$ & $78 / 22$ & 55 & 25 & 20 \\
\hline Poly $\left(\mathrm{MY}_{70} \mathrm{ST}_{30}\right)$ & $70 / 30$ & $72 / 28$ & 70 & 16 & 14 \\
\hline Poly $\left(\mathrm{MY}_{60} \mathrm{ST}_{40}\right)$ & $60 / 40$ & $58 / 42$ & 100 & --- & --- \\
\hline $\operatorname{Poly}\left(\mathrm{MY}_{50} \mathrm{ST}_{50}\right)$ & $50 / 50$ & $51 / 49$ & 100 & --- & --- \\
\hline $\operatorname{Poly}\left(\mathrm{MY}_{30} \mathrm{ST}_{70}\right)$ & $30 / 70$ & $27 / 73$ & 100 & --- & --- \\
\hline Poly $\left(\mathrm{MY}_{0} \mathrm{ST}_{100}\right)$ & $0 / 100$ & $0 / 100$ & --- & --- & --- \\
\hline
\end{tabular}




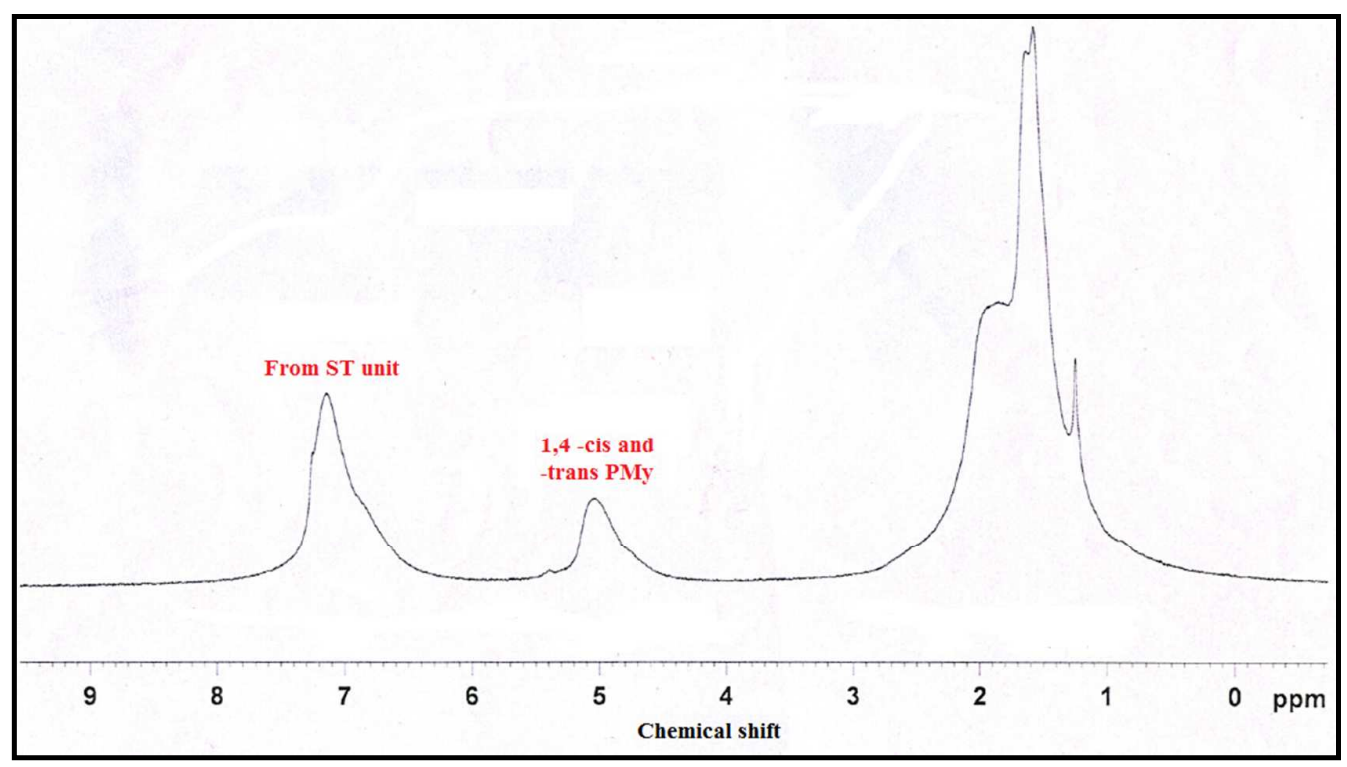

Figure S6. ${ }^{1} \mathrm{H}$ NMR spectrum of Poly $\left(\mathrm{MY}_{60} \mathrm{ST}_{40}\right)$.

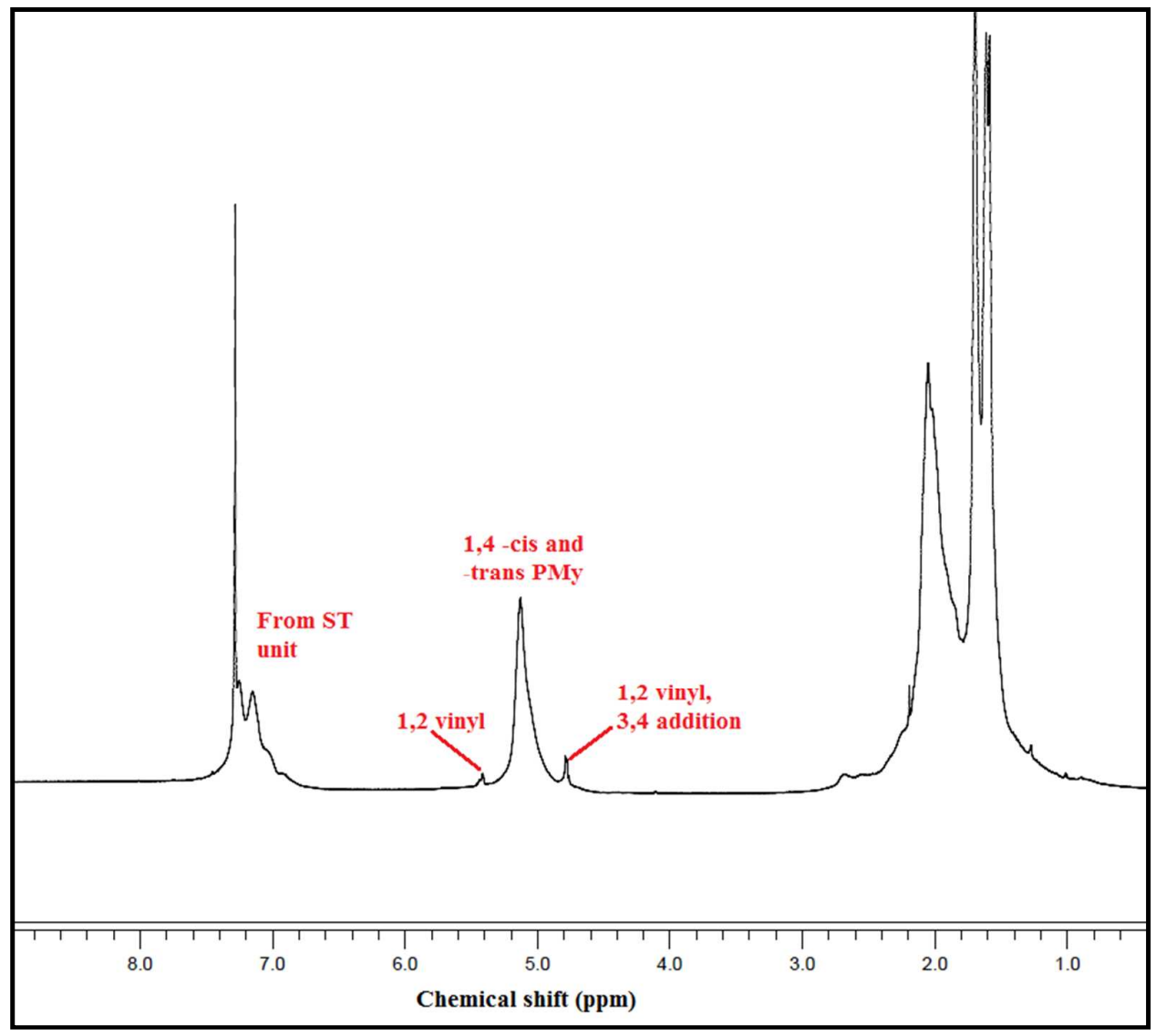

Figure S7. ${ }^{1} \mathrm{H}$ NMR spectrum of Poly $\left(\mathrm{MY}_{70} \mathrm{ST}_{30}\right)$. 


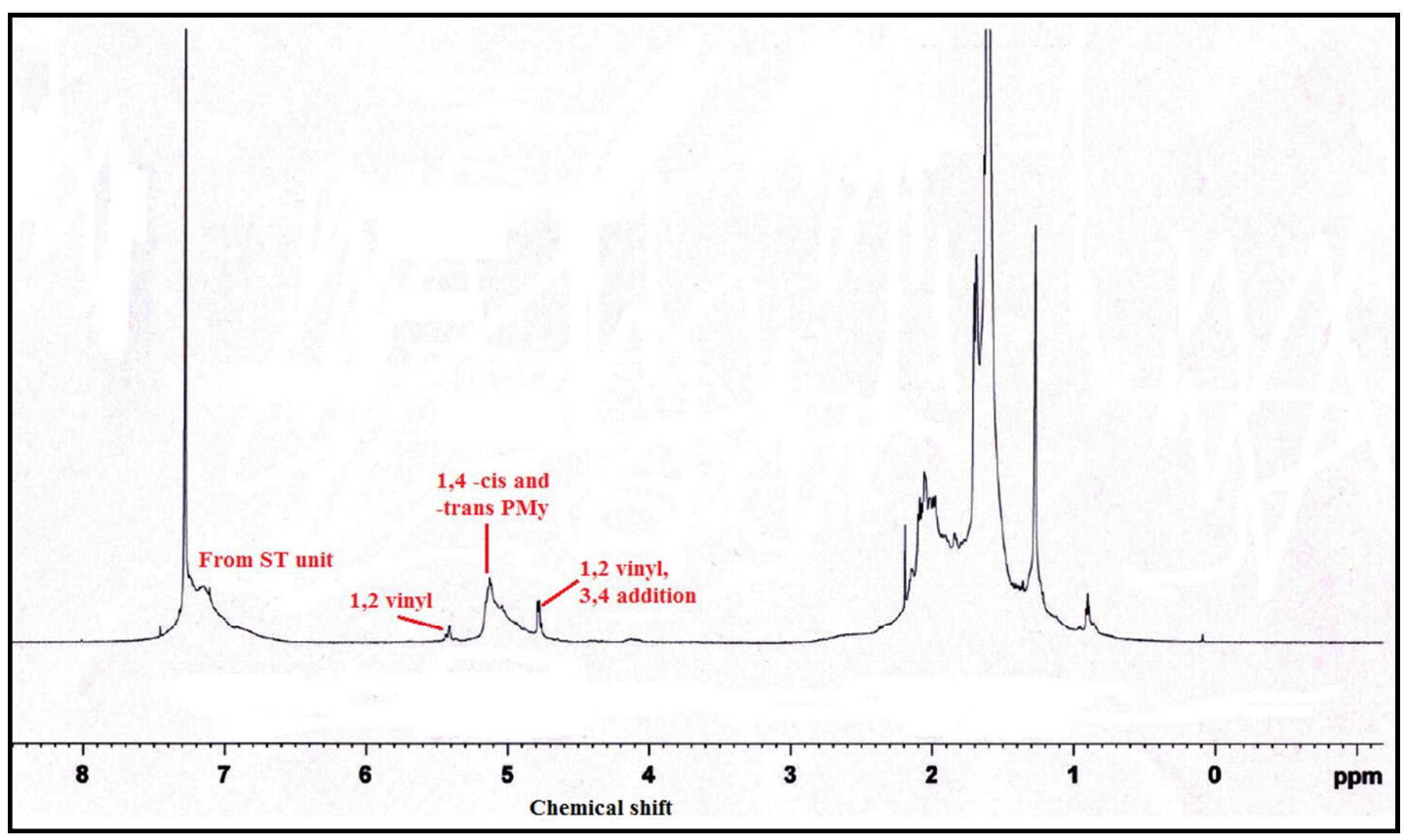

Figure S8. ${ }^{1} \mathrm{H}$ NMR spectrum of Poly $\left(\mathrm{MY}_{80} \mathrm{ST}_{20}\right)$.

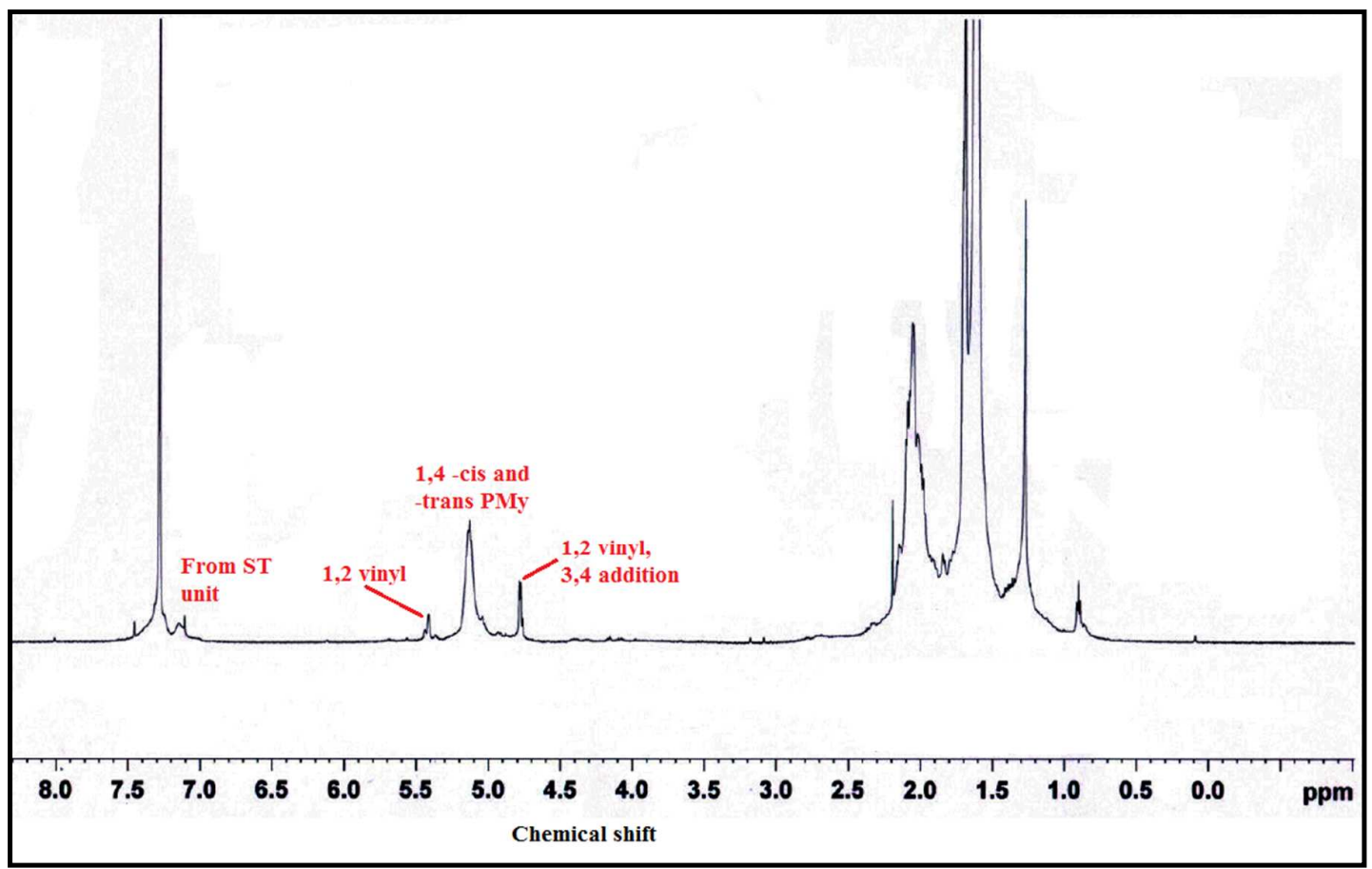

Figure S9. ${ }^{1} \mathrm{H}$ NMR spectrum of Poly $\left(\mathrm{MY}_{90} \mathrm{ST}_{10}\right)$. 


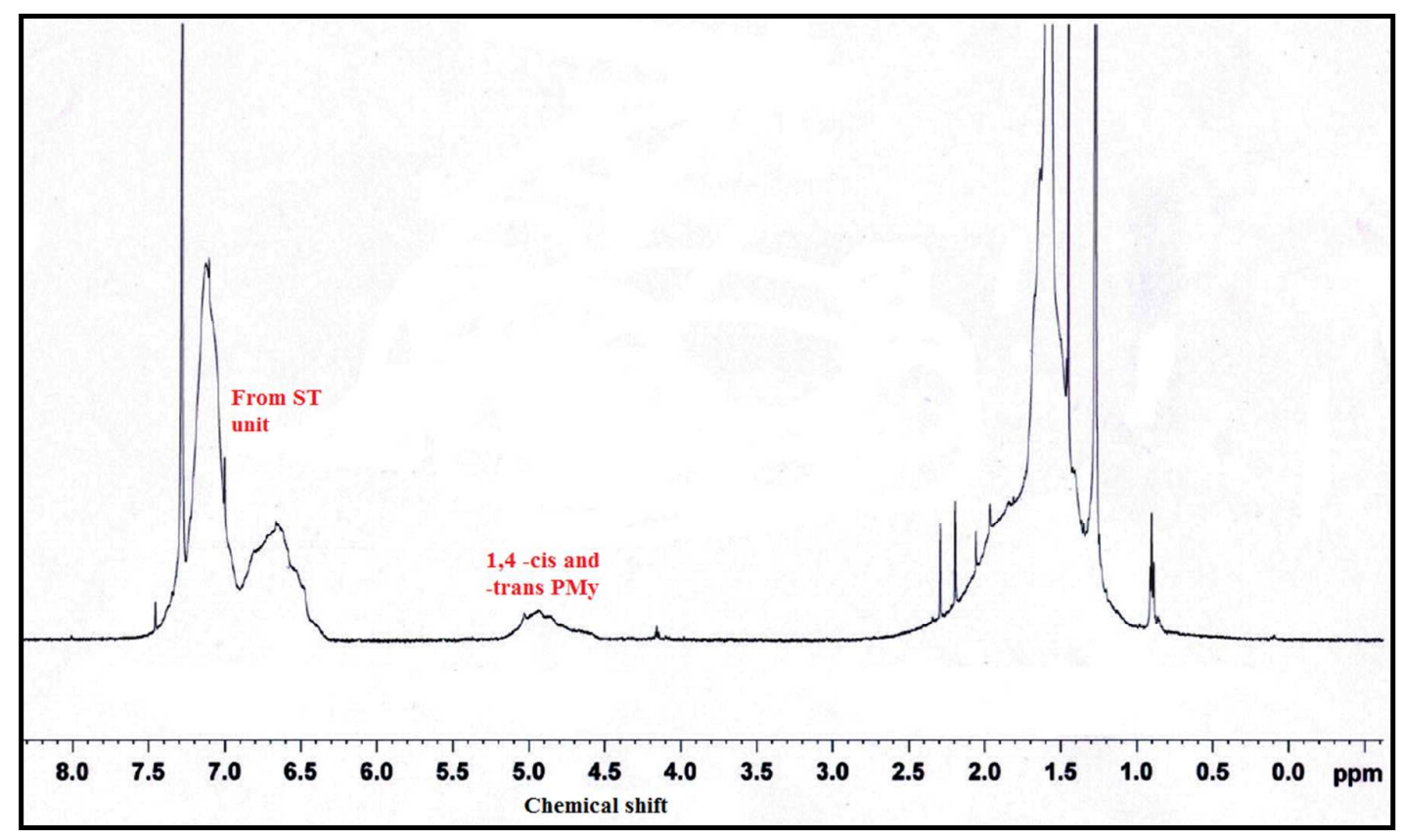

Figure S10. ${ }^{1} \mathrm{H}$ NMR spectrum of Poly $\left(\mathrm{MY}_{30} \mathrm{ST}_{70}\right)$. 


\section{Calculation of monomer reactivity ratios.}

Reactivity ratio of the two monomers $\left(r_{\mathrm{MY}}\right.$ and $\mathrm{r}_{\mathrm{KT}}$ ) was calculated following the method proposed by: Fineman-Ross (FR) and Kelen-Tüdös (KT). Two types of propagating species are possible - one having MY as the propagating end and the other having ST as the propagating end. The radical is represented by an asterisk. Four plausible propagation reactions (based on penultimate model of radical polymerization) can take place:

$$
\begin{aligned}
& \mathrm{MY}^{*}+\mathrm{MY} \rightarrow \mathrm{MY}-\mathrm{MY}^{*}, \text { rate }=\mathrm{k}_{\mathrm{MY}-\mathrm{MY}} \\
& \mathrm{MY}^{*}+\mathrm{ST} \rightarrow \mathrm{MY}-\mathrm{ST}^{*}, \text { rate }=\mathrm{k}_{\mathrm{MY}-\mathrm{ST}} \\
& \mathrm{ST}^{*}+\mathrm{ST} \rightarrow \mathrm{ST}-\mathrm{ST}^{*}, \text { rate }=\mathrm{k}_{\mathrm{ST}-\mathrm{ST}} \\
& \mathrm{ST}^{*}+\mathrm{MY} \rightarrow \mathrm{ST}^{\mathrm{M}} \mathrm{MY}^{*}, \text { rate }=\mathrm{k}_{\mathrm{ST}-\mathrm{MY}}
\end{aligned}
$$

The reactivity ratios of the two monomers can be represented as:

$$
\mathrm{r}_{\mathrm{MY}}=\left(\mathrm{k}_{\mathrm{MY}-\mathrm{MY}} / \mathrm{k}_{\mathrm{MY}-\mathrm{ST}}\right) \text { and } \mathrm{r}_{\mathrm{ST}}=\left(\mathrm{k}_{\mathrm{ST}-\mathrm{ST}} / \mathrm{k}_{\mathrm{ST}-\mathrm{MY}}\right)
$$

According to the FR method, the copolymer composition equation can be rewritten as:

$$
\begin{aligned}
& \frac{F}{f}(f-1)=r_{M Y}\left(\frac{F^{2}}{f}\right)-r_{S T} \\
& \text { Or, } Y_{F R}=r_{M Y} X_{F R}-r_{S T}
\end{aligned}
$$

where $\mathrm{F}=[\mathrm{MY}] /[\mathrm{ST}]$ and $\mathrm{f}=\mathrm{my} / \mathrm{st}$. $[\mathrm{MY}]$ and $[\mathrm{ST}]$ refer to the monomer composition in the feed and 'my' and 'st' refer to the monomer composition in the copolymer. By plotting $\mathrm{Y}_{\mathrm{FR}}$ as ordinate and $\mathrm{X}_{\mathrm{FR}}$ as abscissa generates a straight line, whose slope and intercept provide $\mathrm{r}_{\mathrm{MY}}$ and $\mathrm{r}_{\mathrm{ST}}$ respectively.

The equation for Kelen-Tüdös method is represented as:

$$
\mathrm{Y}_{\mathrm{KT}}=\left(\mathrm{r}_{\mathrm{MY}}+\frac{\mathrm{r}_{\mathrm{ST}}}{\alpha}\right) \mathrm{X}_{\mathrm{KT}}-\frac{\mathrm{r}_{\mathrm{ST}}}{\alpha}
$$

where, $\mathrm{Y}_{\mathrm{KT}}=\frac{\mathrm{Y}_{\mathrm{FR}}}{\alpha+\mathrm{X}_{\mathrm{FR}}}, \mathrm{X}_{\mathrm{KT}}=\frac{\mathrm{X}_{\mathrm{FR}}}{\alpha+\mathrm{X}_{\mathrm{FR}}}$ and $\alpha=\left(\mathrm{X}_{\mathrm{FRmax}} \times \mathrm{X}_{\mathrm{FRmin}}\right)^{1 / 2}$.

A plot of $\mathrm{Y}_{\mathrm{KT}}$ and $\mathrm{X}_{\mathrm{KT}}$ produces a straight line from which both the reactivity ratios can be determined. 
Table S3. Parameters for Calculation of Reactivity Ratio of MY and ST.

\begin{tabular}{cccccc}
\hline $\mathrm{F}=[\mathrm{MY}] /[\mathrm{ST}]$ & $\mathrm{f}=\mathrm{my} / \mathrm{st}$ & $\begin{array}{c}\mathrm{Y}_{\mathrm{FR}}= \\
\mathrm{F}(\mathrm{f}-1) / \mathrm{f}\end{array}$ & $\begin{array}{c}\mathrm{X}_{\mathrm{FR}} \\
=\mathrm{F}^{2} / \mathrm{f}\end{array}$ & $\begin{array}{c}\mathrm{Y}_{\mathrm{KT}}= \\
\mathrm{Y}_{\mathrm{FR}} /\left(\alpha+\mathrm{X}_{\mathrm{FR}}\right)\end{array}$ & $\begin{array}{c}\mathrm{X}_{\mathrm{KT}}= \\
\mathrm{X}_{\mathrm{FR}} /\left(\alpha+\mathrm{X}_{\mathrm{FR}}\right)\end{array}$ \\
\hline 6.878 & 8.230 & 6.042 & 5.748 & 0.862 & 0.820 \\
3.057 & 3.604 & 2.209 & 2.593 & 0.573 & 0.672 \\
1.783 & 2.088 & 0.929 & 1.522 & 0.334 & 0.547 \\
1.146 & 1.359 & 0.303 & 0.966 & 0.136 & 0.433 \\
0.746 & 0.897 & -0.087 & 0.650 & -0.046 & 0.340 \\
0.327 & 0.385 & -0.522 & 0.278 & -0.339 & 0.180 \\
\hline
\end{tabular}

Where, $\alpha=\left(X_{\text {FRmax }} \times X_{\text {FRmin }}\right)^{1 / 2}=1.263$

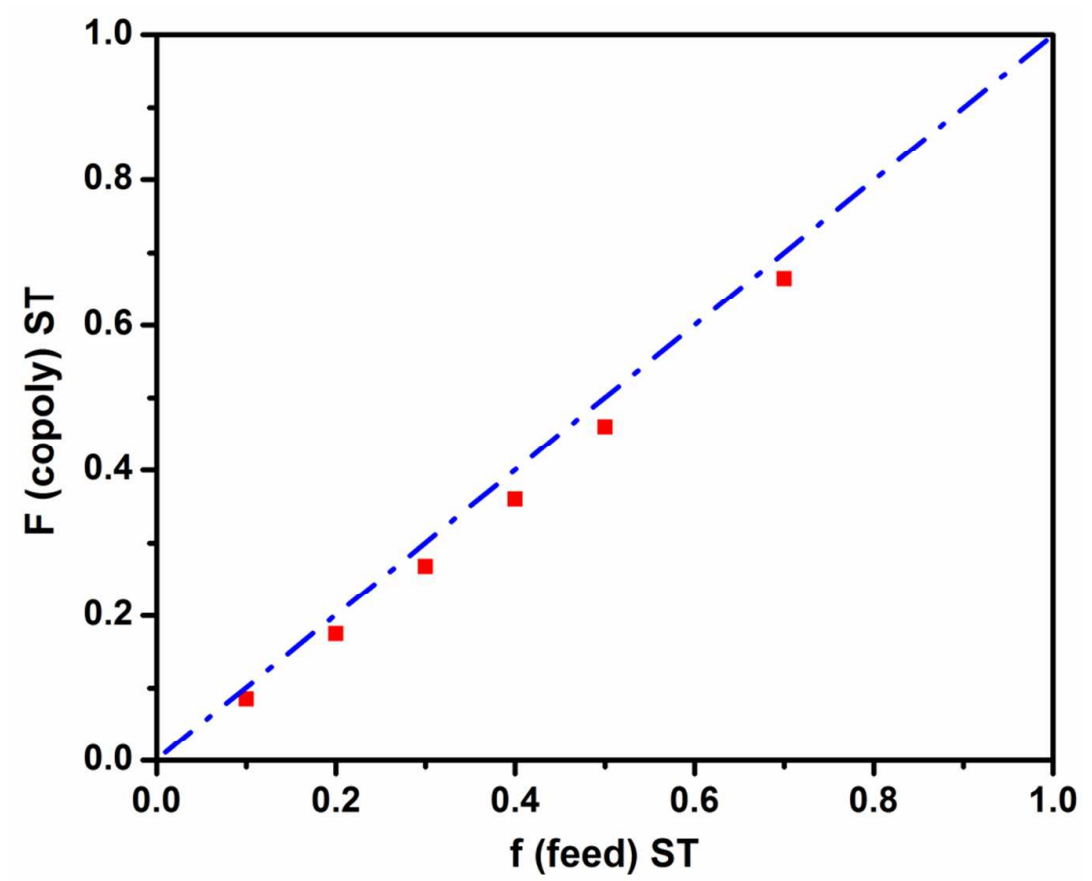

Figure S11. Plot of ST mole fractions in feed and copolymer. (The theoretical curve for an ideal copolymerization is given as a blue dotted line). 


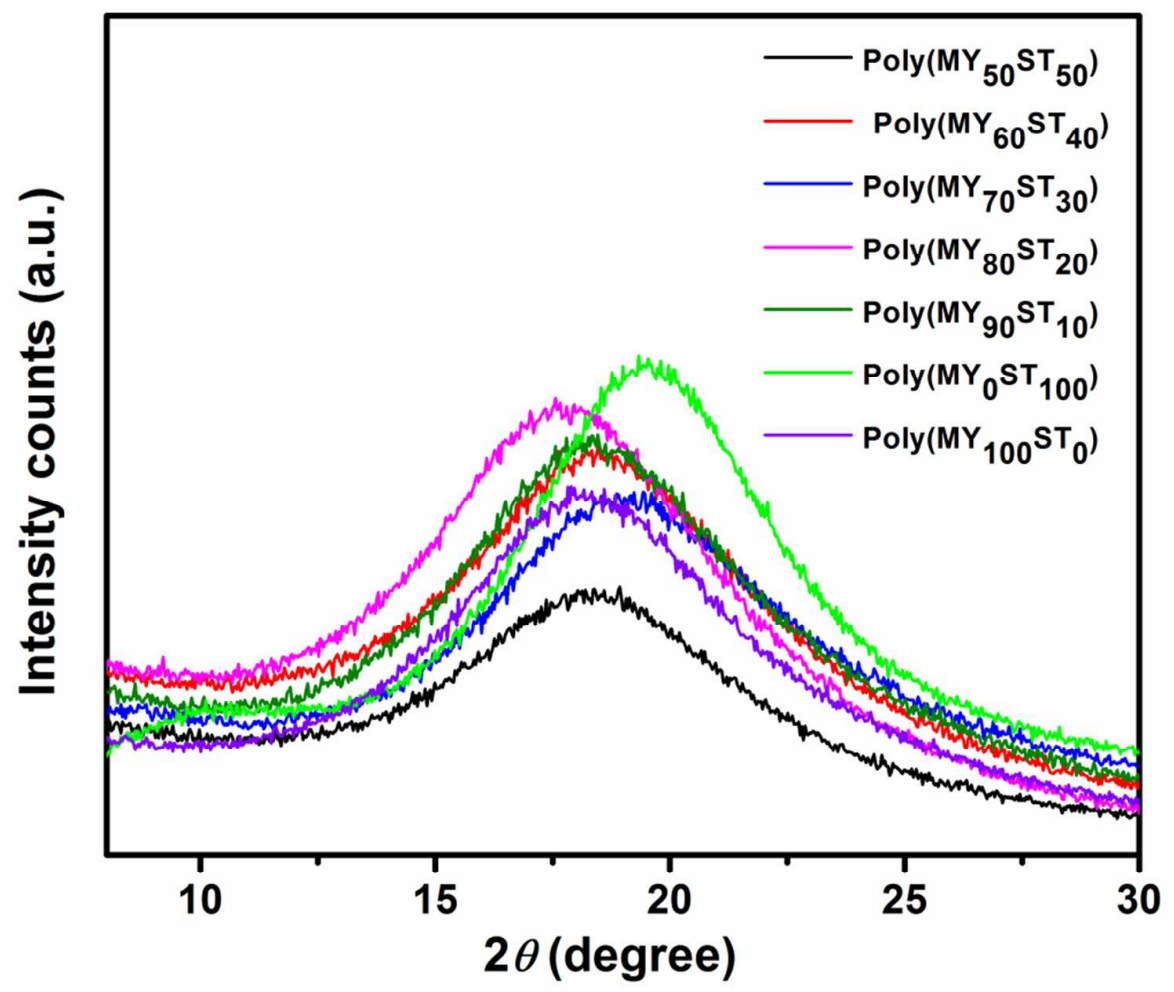

Figure S12. X-ray diffractograms of various synthesized polymers.

Table S4. Glass Transition Temperature of Various Polymers.

glass transition temperature

polymer

DSC MCR

$\left({ }^{\circ} \mathrm{C}\right) \quad\left({ }^{\circ} \mathrm{C}\right)$

Flory-Fox equation

$\left({ }^{\circ} \mathrm{C}\right)$

\begin{tabular}{lccc}
\hline Poly $\left(\mathrm{MY}_{100} \mathrm{ST}_{0}\right)$ & -69.0 & -57.2 & --- \\
Poly $\left(\mathrm{MY}_{90} \mathrm{ST}_{10}\right)$ & -60.9 & -39.8 & -60.2 \\
Poly $\left(\mathrm{MY}_{80} \mathrm{ST}_{20}\right)$ & -51.6 & -25.5 & -38.9 \\
Poly $\left(\mathrm{MY}_{70} \mathrm{ST}_{30}\right)$ & -35.2 & -15.6 & -31.3 \\
Poly $\left(\mathrm{MY}_{60} \mathrm{ST}_{40}\right)$ & -15.0 & 5.2 & -20.3 \\
Poly $\left(\mathrm{MY}_{50} \mathrm{ST}_{50}\right)$ & 10.0 & 24.3 & -9.8 \\
Poly $\left(\mathrm{MY}_{30} \mathrm{ST}_{70}\right)$ & 37.2 & --- & 33.6 \\
Poly $\left(\mathrm{MY}_{0} \mathrm{ST}_{100}\right)$ & 103.8 & --- & --- \\
\hline
\end{tabular}




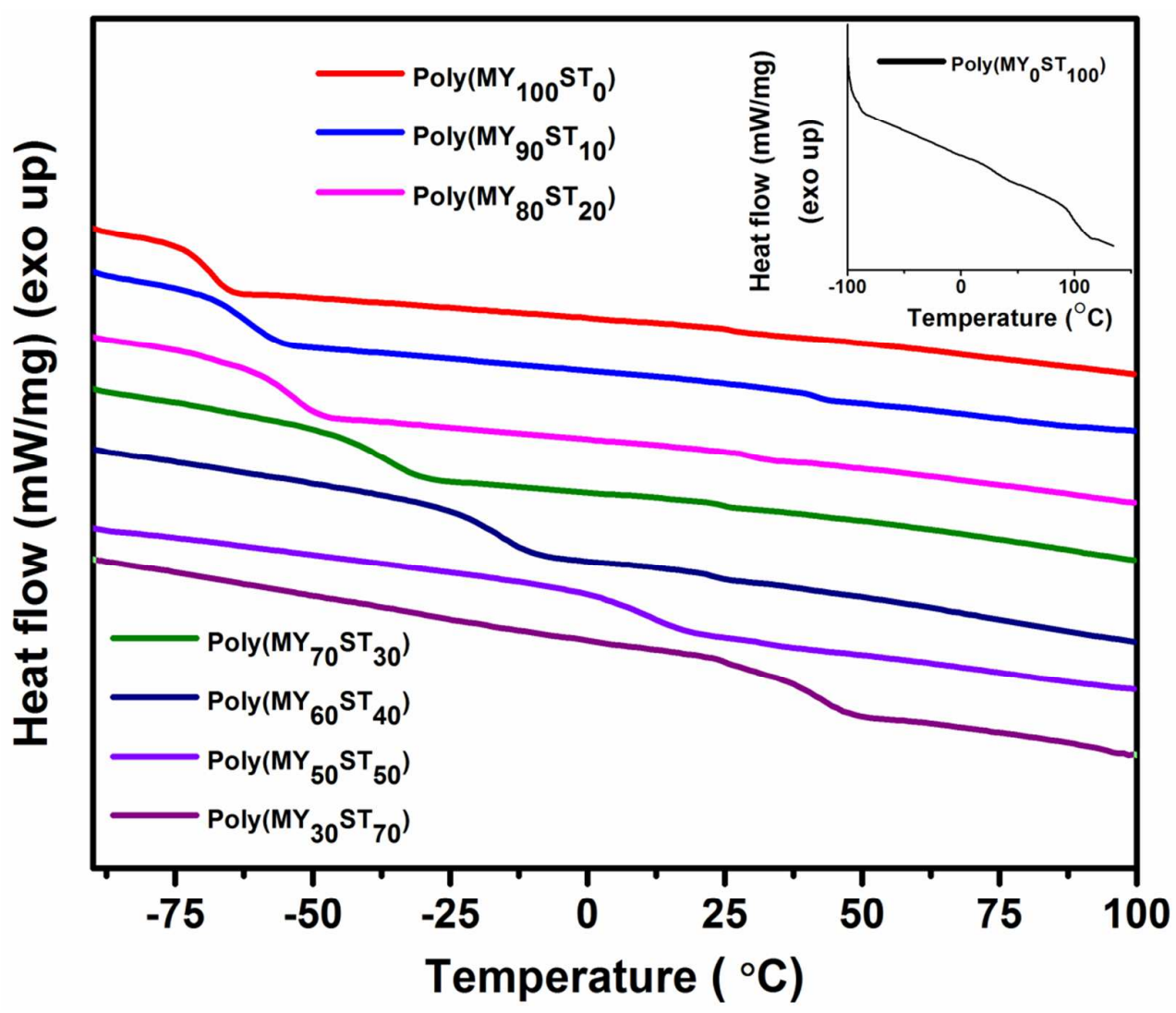

Figure S13. DSC traces of various homo and co-polymers (inset shows the DSC thermogram of the synthesized polystyrene sample).

\section{Molecular dynamics simulation.}

The theoretical calculations in MD simulation were executed by the Condensed-phase Optimized Molecular Potentials for Atomistic Simulation Studies (COMPASS) force field. ${ }^{1}$ This method has been widely used to optimize and predict the structural, conformational, and thermo-physical condensed phase properties of macromolecules. ${ }^{2,3}$ According to this method, the total potential energy $\left(E_{\mathrm{T}}\right)$ is presented by the following equation:

$$
\begin{aligned}
E_{\mathrm{T}} & =E_{\text {bond }}+E_{\text {nonbond }}+E_{\text {cross }} \\
& =E_{\mathrm{b}}+E_{\mathrm{\theta}}+E_{\phi}+E_{\mathrm{vdw}}+E_{\text {coulomb }}+E_{\text {cross }}
\end{aligned}
$$

where $E_{\mathrm{b}}$ is the bond stretching energy, $E_{\mathrm{\theta}}$ is the angle bending energy and $E_{\phi}$ is the dihedral torsion energy. The sum of these three terms is the bonded energy or $E_{\mathrm{bond}} . E_{\mathrm{vdw}}$ is the van der 
Waals energy, $E_{\text {coulomb }}$ is the Coulombic energy and the sum of these two contributions is the nonbonded energy $E_{\text {nonbond. }} E_{\text {cross }}$ is the energy of cross terms between any two of the bonded items, such as the bond-angle cross term and the bond-bond cross term.

The geometry of the structures was optimized by steepest descent method. To minimize the unwanted contacts, three configurations of minimum energy were selected after energy optimization to get the cell with the lowest energy. The Ewald summation was adopted for the electrostatic interactions with an accuracy of $0.001 \mathrm{kcal} / \mathrm{mol}$, and the atombased summation was applied for the van der Waals interactions with a cut off distance of 12.5 $\AA$, a spline width of $1 \AA$, and a buffer width of $0.5 \AA$. After annealing of the AC, the MD simulation was carried out for 1.25 ps at $1 \mathrm{~atm}$. Then, the system was cooled down to $80 \mathrm{~K}$ with $20 \mathrm{~K}$ interval. The thermostat and barostat were maintained by Andersen and Berendsen method respectively. At each temperature, $1.25 \mathrm{ps}$ MD simulation was performed at a constant pressure of 1 bar and with a time step of $0.25 \mathrm{fs}$.

Table S5. Characteristic Degradation Temperatures and Percent Residue at $750{ }^{\circ} \mathrm{C}$

\begin{tabular}{ccccc}
\hline polymer & $\mathrm{T}_{20}\left({ }^{\circ} \mathrm{C}\right)$ & $\mathrm{T}_{\max }\left({ }^{\circ} \mathrm{C}\right)$ & $\begin{array}{c}\mathrm{dW} / \mathrm{dT}\left(\% /{ }^{\circ} \mathrm{C}\right) \\
\text { at } \mathrm{T}_{\max }\end{array}$ & $\begin{array}{c}\% \text { residue at } \\
750{ }^{\circ} \mathrm{C}\end{array}$ \\
\hline Poly $\left(\mathrm{MY}_{100} \mathrm{ST}_{0}\right)$ & 280 & 415 & 0.7 & 4.32 \\
Poly$\left(\mathrm{MY}_{90} \mathrm{ST}_{10}\right)$ & 360 & 400 & 1.1 & 1.90 \\
Poly $\left(\mathrm{MY}_{80} \mathrm{ST}_{20}\right)$ & 360 & 395 & 1.3 & 0.00 \\
Poly $\left(\mathrm{MY}_{70} \mathrm{ST}_{30}\right)$ & 353 & 391 & 1.2 & 1.67 \\
Poly$\left(\mathrm{MY}_{60} \mathrm{ST}_{40}\right)$ & 366 & 391 & 1.4 & 0.01 \\
Poly $\left(\mathrm{MY}_{50} \mathrm{ST}_{50}\right)$ & 365 & 389 & 1.5 & 0.10 \\
Poly $\left(\mathrm{MY}_{0} \mathrm{ST}_{100}\right)$ & 406 & 423 & 3.5 & 0.22 \\
\hline
\end{tabular}



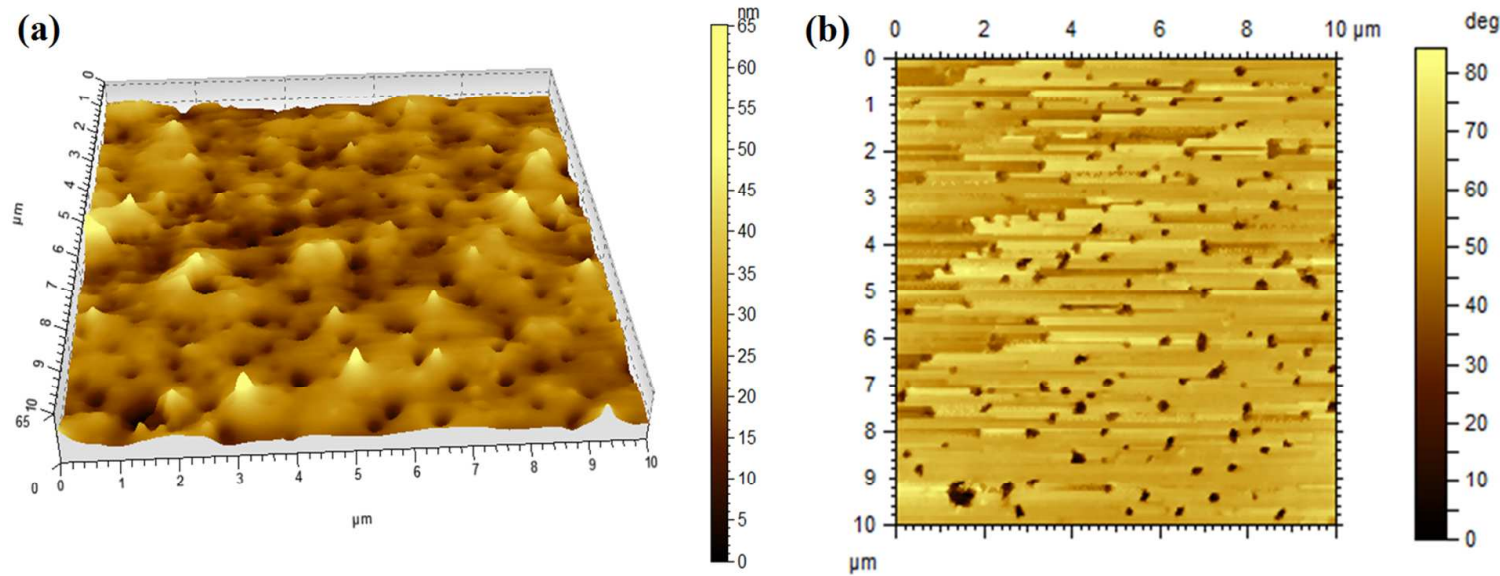

Figure S14. AFM image of the poly $\left(\mathrm{MY}_{50} \mathrm{ST}_{50}\right)$ sample (a) 3D topography (b) Phase image
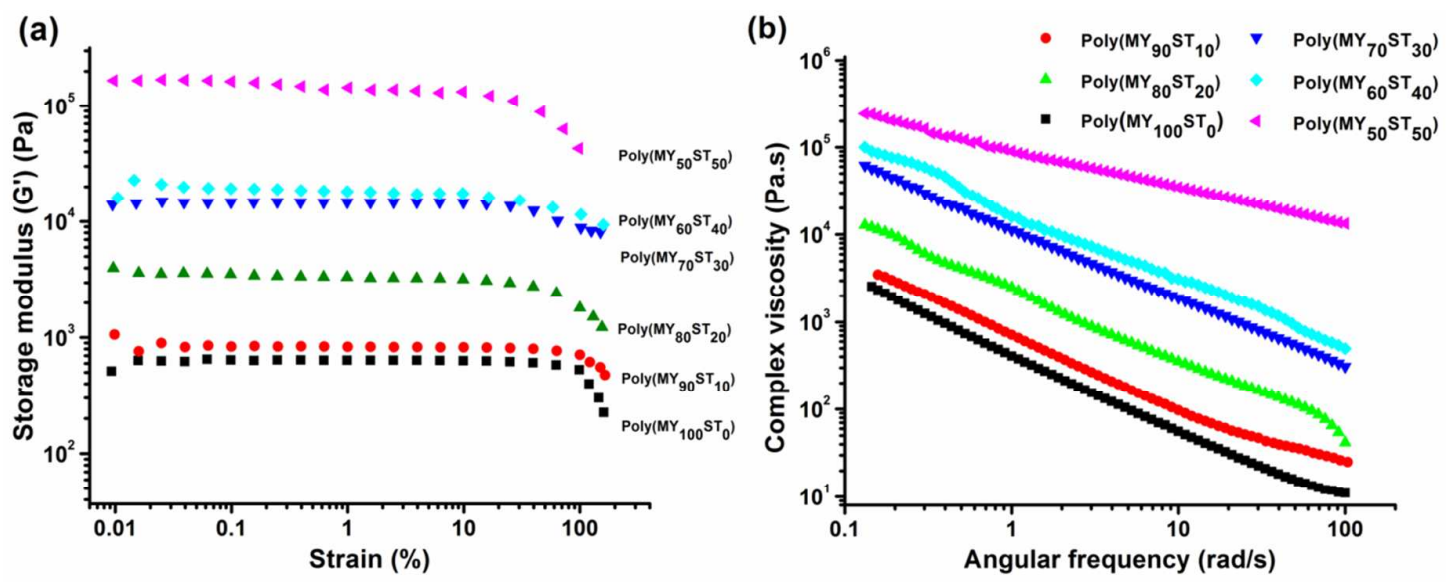

Figure S15. Room temperature plot of (a) storage modulus as a function of percent strain and (b) complex viscosity versus angular frequency for various copolymers 


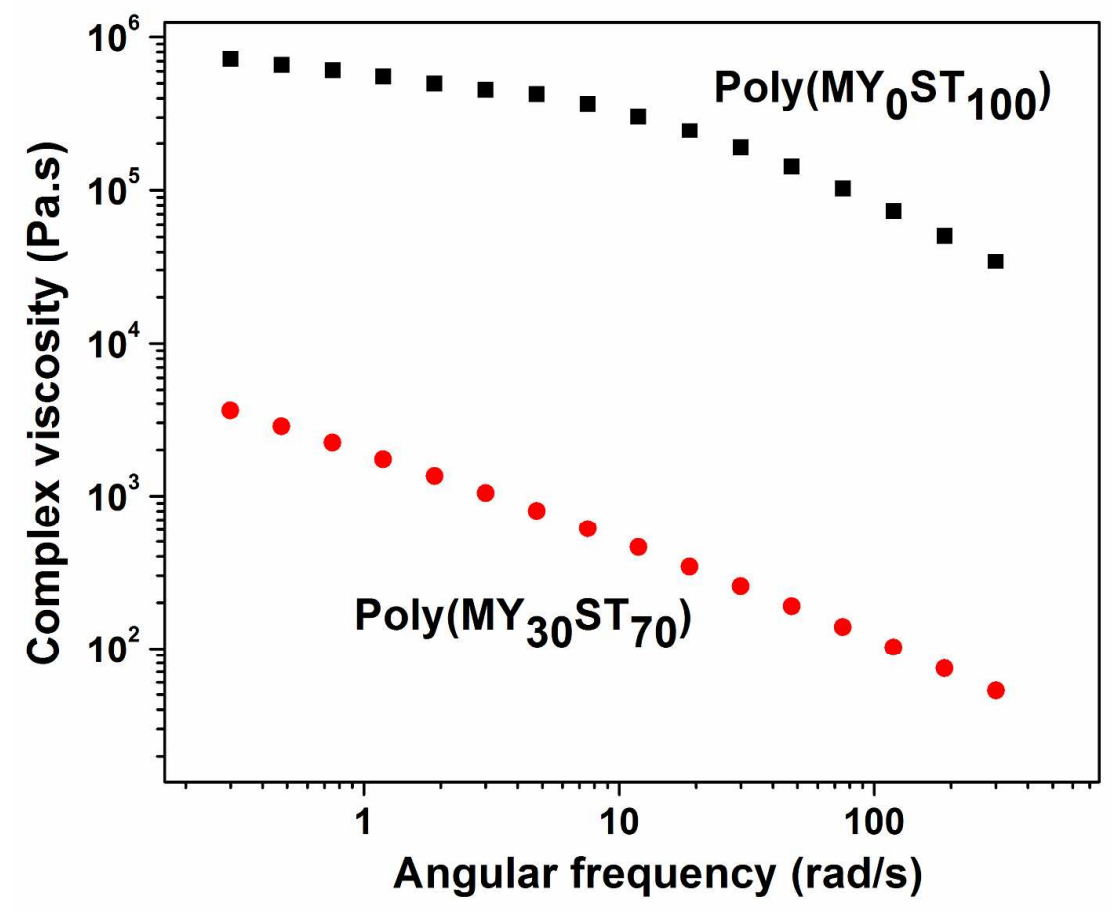

Figure S16. Plot of complex viscosity versus angular frequency for Poly $\left(\mathrm{MY}_{0} \mathrm{ST}_{100}\right)$ and Poly $\left(\mathrm{MY}_{30} \mathrm{ST}_{70}\right)$ samples at $110{ }^{\circ} \mathrm{C}$.

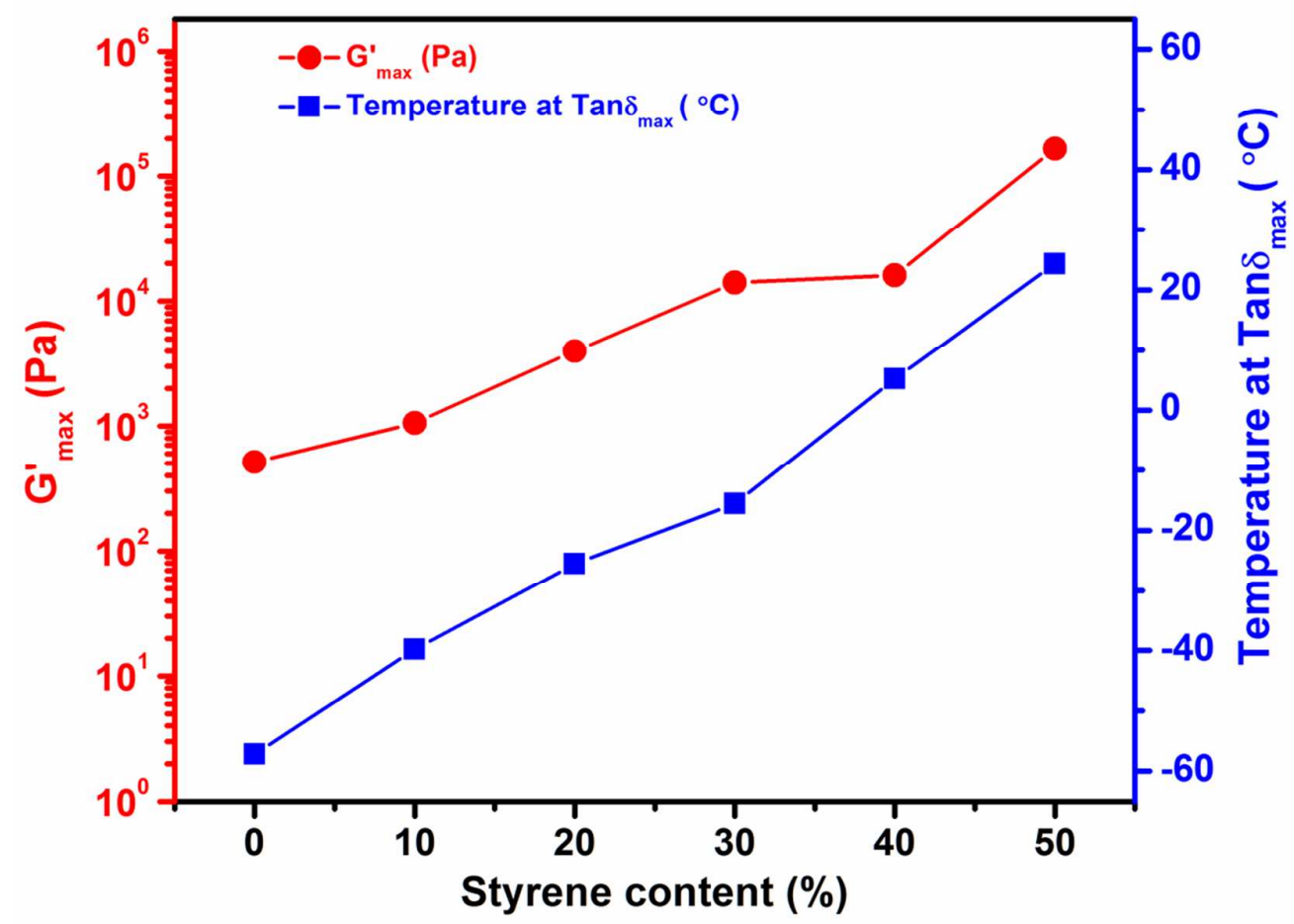

Figure S17. Variation of $\mathrm{G}_{\max }^{\prime}$ and temperature at $\operatorname{Tan}_{\max }$ with styrene content. 


\section{REFERENCES}

(1) Sun, H. COMPASS: An ab-initio Force-Field Optimized for Condensed-Phase Applications Overview with Details on Alkane and Benzene Compounds. J. Phys. Chem. B 1998, 102, 7338-7364.

(2) Jawalkar, S. S.; Adoor, S. G.; Sairam, M.; Nadagouda, M. N.; Aminabhavi, T. M. Molecular Modeling on the Binary Blend Compatibility of Poly(vinyl alcohol) and Poly(methyl methacrylate): An Atomistic Simulation and Thermodynamic Approach. J. Phys. Chem. B 2005, 109, 15611-15620.

(3) Prathab, B.; Aminabhavi, T. M.; Parthasarathi, R.; Manikandan, P.; Subramanian, V. Molecular Modeling and Atomistic Simulation Strategies to Determine Surface Properties of Perfluorinated Homopolymers and Their Random Copolymers. Polymer 2006, 47, 69146924. 